\title{
Mild head injury - a close relationship between motor function at 1 week post-injury and overall recovery at 3 and 6 months
}

\author{
Marcus H. Heitger ${ }^{\mathrm{a}, \mathrm{b}, *}$, Richard D. Jones ${ }^{\mathrm{a}, \mathrm{b}, \mathrm{c}}$, John C. Dalrymple-Alford ${ }^{\mathrm{a}, \mathrm{d}}$, \\ Chris M. Frampton ${ }^{\mathrm{a}, \mathrm{b}}$, Michael W. Ardagh ${ }^{\mathrm{a}, \mathrm{e}}$, Tim J. Anderson ${ }^{\mathrm{a}, \mathrm{b}, \mathrm{f}}$ \\ a Van der Veer Institute for Parkinson's and Brain Research, Christchurch, New Zealand \\ b Department of Medicine, Christchurch School of Medicine and Health Sciences, Christchurch, New Zealand \\ c Department of Medical Physics and Bioengineering, Christchurch Hospital, Christchurch, New Zealand \\ d Department of Psychology, University of Canterbury, Christchurch, New Zealand \\ e Emergency Department, Christchurch Hospital, Christchurch, New Zealand \\ ${ }^{\mathrm{f}}$ Department of Neurology, Christchurch Hospital, Christchurch, New Zealand
}

Received 2 June 2006; received in revised form 4 October 2006; accepted 8 November 2006

Available online 17 January 2007

\begin{abstract}
Based on previous findings of impaired eye and arm motor control after mild closed head injury (CHI), this study examined whether early eye and arm motor function, and the level of post-injury cerebral dysfunction manifested in motor control, relates systematically to recovery at 3 and 6 months after mild CHI.

At 1 week post-injury, we assessed oculomotor function, upper-limb visuomotor performance, and cognitive status in 37 mild CHI patients. Re-examination at 3 and 6 months determined outcome in terms of postconcussional symptoms and performance of everyday tasks, as assessed by the Rivermead Postconcussion Symptoms Questionnaire, the Rivermead Head Injury Follow-up Questionnaire and the SF-36 Health Survey. We then examined the association of early motor function, cognitive status and self-reported health condition with outcome using linear regression.

Motor-based regression models explained a high proportion of the variance in outcome (70-89\%), with motor function at 1 week being more closely related to outcome at 3 and 6 months than early psychometric assessment (13-32\%) or self-reported health status (54-79\%). These motor-based models incorporated subcortical/subconscious motor functions alongside motor functions that are subject to volitional control and are primarily mediated by frontal, parietal and temporal cortical brain regions.

Early assessment of eye and arm motor function may help in improving accuracy of outcome prediction after mild CHI. Such assessment may assist in the better targeting of early health care intervention and help decrease head-trauma-related morbidity and rehabilitation costs. (C) 2006 Elsevier B.V. All rights reserved.
\end{abstract}

Keywords: Head injury; Recovery; Motor function; Oculomotor; Upper-limb visuomotor; Prediction of outcome

\section{Introduction}

Mild closed head injury (CHI) is a significant cause of morbidity with hospital admission rates of between 100 and

\footnotetext{
* Corresponding author. Van der Veer Institute for Parkinson's and Brain Research, PO Box 2682, Christchurch, New Zealand. Tel.: +64 3378 6074; fax: +6433786080

E-mail address: marcus.heitger@chmeds.ac.nz (M.H. Heitger).
}

300 cases per year per 100,000 population [1,2] and considerable costs for clinical treatment and care. Although most patients with mild $\mathrm{CHI}$ recover relatively soon after the injury and return to work and social activities, a number of patients experience disabling persistent postconcussional complaints of both a physical and psychological nature beyond the first weeks following the injury, and sometimes for months or even years [3-18]. During the first 6 months postinjury, an estimated $20-40 \%$ of mild CHI cases suffer such 
consequences $[4,7-9,15,19-21]$. This impacts significantly on daily life and ability to return to work $[3,22]$ and has financial implications for public health care providers [23].

Many studies have tried to identify early predictors of outcome from mild CHI. In keeping with the prediction techniques applied in the context of moderate-to-severe head trauma, studies aiming to predict outcome after mild CHI have examined clinical measures of trauma severity such as Glasgow Coma Scale (GCS), duration of loss of consciousness (LOC) and degree of post-traumatic amnesia (PTA) $[7,15,21,24-29]$. Others have employed early symptomatic complaints or biochemical markers [16,21,30-32], and both functional and structural imaging techniques [33-36]. However, all of these approaches are limited in their ability to predict outcome after mild head trauma. Neuropsychological assessment has been frequently applied in mild head trauma to study the functional impact of the injury. More recently, computerised neuropsychological assessment tools aiming to gauge injury status and ability to return to play in sport-related injury have shown promising results in terms of demonstrating impaired cognitive function, tracking functional recovery, and improving acute and post-acute management of athletes who have suffered a mild head injury [3739]. However, neuropsychological assessment is vulnerable to pre-morbid intelligence and other factors such as age, level of education, state of employment and socioeconomic status, and the application of neuropsychological assessment to predict outcome after mild head injury has proven problematic $[25,29,40-43]$.

We have previously reported that mild $\mathrm{CHI}$ impairs the complex cerebral networks for eye and arm motor control at 1 week post-injury, causing deficits in volitional saccades, oculomotor smooth pursuit, and upper-limb visuomotor function [44-47]. These motor deficits occur independently of neuropsychological impairment after mild CHI [46]. The profile of motor deficits, in terms of composition of impaired and preserved motor functions, indicated that the adverse bio-physical impact of closed head trauma on the brain $[48,49]$ manifests in eye and arm movement performance and that motor function relates closely to the functional status of the brain after mild CHI [46].

Based on these findings, we conducted a longitudinal study following patients with mild CHI throughout the first year post-injury in order to examine the recovery profile of such motor deficits. The results showed that motor deficits, compared to healthy controls, are detectable up to a year post-injury [45], independent of psychometric status. A second objective of this study was to examine the association between early motor status and overall recovery, and to see whether there is a systematic relationship between eye and arm motor function at approximately 1 week post-injury and outcome after mild CHI. Based on the view that functionality of the brain at an early stage post-injury may relate to, and be indicative of, the course of recovery in the following months, we hypothesised that it may be possible to use the impact of $\mathrm{CHI}$ on the complex cerebral networks for motor control as an objective indicator for the functional status of the brain after mild CHI, and subsequently relate early eye and motor function to later recovery. In addition to motor function, we assessed the relationship of self-reported health condition and neuropsychological status at 1 week post-injury with levels of recovery at 3 and 6 months post-injury. These points in time were chosen in keeping with the notion that most of the recovery following mild $\mathrm{CHI}$ is likely to occur within the first 6 months [50] and in line with examples of previous studies aiming to predict and/or assess outcome after mild CHI [7,10,15,16,21,22,25,26,29,32,51-54].

\section{Participants and methods}

\subsection{Participants}

Thirty seven subjects ( 13 female and 24 male) with mild CHI (score on the Glasgow Coma Scale [GCS] 13: 4 cases, 14: 12 cases, 15: 21 cases) were recruited from patients presenting with acute head injury to Christchurch Hospital (the principal hospital for a regional population of over 400,000). Patients had to have a GCS score of between 13 and 15 on first assessment, without falling below 13 at any consecutive assessment at the hospital. At the time of recruitment, no standardised method was in practice to assess duration of post-traumatic amnesia (PTA) in patients presenting with mild head injury to the Emergency Department at Christchurch Hospital and PTA duration was not routinely noted in patient files (apart from brief comments on the lack of recall of the injury-event if applicable). Hence, an iterative process was used to (a) confirm that PTA was less than $24 \mathrm{~h}$ (the only required screening criterion) and (b) provide an approximate duration of PTA (the GCS score was the principal factor for $\mathrm{CHI}$ classification). At the initial pre-recruitment interview at the hospital, patients were asked about their first memory following the injury. If the remembered event fell within a $24 \mathrm{~h}$ period, it was assessed whether the patient remembered being at the scene after the accident/regaining consciousness, being helped by others (e.g., extraction from a vehicle, somebody clearing their bike off the street or calling an ambulance), the arrival of the ambulance (if applicable, standard response time of ambulances within city boarders taken as time approximation), being in the ambulance, arriving at the hospital (time was recorded on admission sheet as was time of accident in the case of MVAs and most sport accidents), treatment events for which the time was noted on the patient chart, and being served a meal (usually dinner or breakfast for patients who stayed overnight). All patients had experienced PTA ranging between $2 \mathrm{~min}$ and $22 \mathrm{~h}$ (median $15 \mathrm{~min}$ ) and 32 patients had a confirmed loss of consciousness (LOC, median $2.0 \mathrm{~min}$, range $0.5-15 \mathrm{~min}$ ). Duration of LOC was, in most cases, established from the available patient records. Most of the patients, in particular those involved in sports and motor vehicle accidents, had a witnessed LOC, with duration recorded in the ambulance/patient notes. Mean age was 29.1 years (SD 12.7, range 15-56 years) and 
mean years of education 13.6 (SD 2.56, range 8-19 years). All patients were either employed or attended institutions for secondary or tertiary education and none was involved in litigation. Other potential participants were excluded if there was evidence of any influence of alcohol or psychoactive drugs at time of injury (as the effects of alcohol/drugs may distort scores on the GCS), regular intake of psychoactive drugs or history of drug abuse (risk of GCS distortion; influence of psychoactive medications on eye movement control), central neurological disorder or psychiatric condition (several such conditions are known to affect eye movement patterns in particular), structural brain damage or haematoma on CT head scan (obtained in nine participants and normal in all cases), signs of vestibular dysfunction or oculomotor or somatomotor deficits upon clinical examination, presence of strabismus, visual acuity worse than $6 / 12$, skull fracture, or prior history of mild, moderate or severe head injury with persisting symptoms or complaints. These criteria were consistent with a previous study [46].

Throughout the study, none of the participants was hospitalised or developed secondary health problems related to other causes which could have influenced any of the measures. Subjects were offered compensation for travel costs to attend the testing at the hospital but received no other payment. The project was approved by the Canterbury Ethics Committee and written consent was obtained from all participants.

\subsection{Motor assessment}

\subsubsection{Oculomotor testing}

The assessment methods, paradigm parameters, and key measures of motor performance were identical to an earlier study and have been described in detail elsewhere $[44,46,55]$. Eye movements were recorded using an IRIS infrared limbus tracker (Skalar Medical, BV, Delft, The Netherlands) [56]. We incorporated paradigms for reflexive saccades (44 saccades, stimuli jumping randomly by $5,10,15,20,25$ or $30^{\circ}$ in a horizontal direction, at intervals varying pseudorandomly between 1.0 and $1.6 \mathrm{~s}$ ), antisaccades (32 saccades, stimuli at 5 and $15^{\circ}$ off centre, at intervals varying pseudorandomly between 1.0 and $1.6 \mathrm{~s}$, balanced for left and right), memoryguided sequences of saccades ( 6 different sequences, each with 4 steps, duration of $1.0 \mathrm{~s}$ per step, each sequence practised 5 times, then performed once, followed by presentation of the next sequence), self-paced saccades ('do-as-many-as-possible'-self-pacing for $30 \mathrm{~s}$ between 2 stationary targets, $\pm 15^{\circ} \mathrm{off}$ centre) as well as sine and random oculomotor smooth pursuit (sine at 40 and $60 \%$ seak velocity, and random smooth pursuit, mean peak velocity $80^{\circ} / \mathrm{s}$, each task $40 \mathrm{~s}$ duration). The only change from our earlier study was the presentation of the antisaccade paradigm by way of video screen using different colours for fixation (red) and antisaccade stimuli (green), rather than by red LED (light-emitting diode) bar.

Mean values of the key measures over all trials in a particular test paradigm were used in analyses. Each paradigm was performed only once by each subject. Before the test proper, subjects were shown an example of each paradigm in order to familiarise them with the task requirements. Several key measures were taken including saccade latency (ms) (reflexive, anti- and self-paced saccades), saccade velocity $(\%)$ (reflexive, anti- and self-paced saccades), number of self-paced saccades within $30 \mathrm{~s}$, directional errors (antisaccades and memory-guided sequences), and, for all saccadic paradigms, the mean absolute position error of the final eye position $\left(\mathrm{PE}=\left|\left(\mathrm{EP}_{\mathrm{fin}}-\mathrm{SP}\right) / \mathrm{SP}\right| * 100\right)$, and gain (eye position/stimulus position) of the primary saccade $\left(G_{\mathrm{p}}=\mathrm{EP}_{\text {prim }} / \mathrm{SP}\right)$ and final eye position $\left(\mathrm{G}_{\mathrm{F}}=\mathrm{EP}_{\text {fin }} / \mathrm{SP}\right)$, where $\mathrm{EP}_{\text {prim }}$ is the eye position after the initial saccade, $\mathrm{EP}_{\text {fin }}$ is the final eye position and $\mathrm{SP}$ is the stimulus position [46]. For memory-guided sequences, an amplitude error (AE) was also derived for all sequence steps [44], based on the view that a sequence of saccades may be perceived as a motor pattern of amplitudes and rhythm performed in an automated manner, irrespective of spatial validation. The $\mathrm{AE}$ is based on movement size rather than the absolute size of error between final fixation and stimulus position $(\mathrm{AE}=$ mean difference [\%] between observed saccadic vs. stimulus amplitude) [44]. An 'absolute time index' (ATI= subject's total response time/duration of the sequence) was also calculated for memory-guided sequences [44]. Key measures for oculomotor smooth pursuit were the average eye peak velocity $(\%)$ after removal of all saccades from the tracking performance and the tracking lag (ms).

Overall, the oculomotor assessment provided 35 variables (29 variables resulting from the saccadic paradigms and 6 variables from oculomotor smooth pursuit) for the pool of independent measures for the regression analyses.

\subsubsection{Upper-limb visuomotor testing}

The test set-up and paradigm parameters were identical to our previous study [46], comprising tests of visual acuity, visual perception and resolution, basic arm motor function (movement speed and steadiness) and several one-dimensional (1D) visuomotor tracking tasks (sine and random preview/non-preview and step tracking) $[46,57]$.

Subjects were seated in front of a colour monitor with an eye-to-screen distance of $132 \mathrm{~cm}$ [46,57]. The 1D tracking tasks used a steering wheel as subjects' output sensor, which moved a vertical white arrow (16 mm high, $11 \mathrm{~mm}$ wide) horizontally on a black background $[46,57]$. Subjects placed their preferred hand at a fixed position on the steering wheel [46,57]. Key measures for all 1D tracking tasks were the mean absolute error ( $\mathrm{mm}$; horizontal distance between arrow head and target) and tracking lag (ms) [46]. The upper-limb visuomotor assessment provided 13 variables for the pool of independent measures for the regression analyses.

\subsection{Neuropsychological tests}

Attention, working memory, episodic memory and speed of information processing were assessed using the Paced Auditory Serial Addition Task (PASAT) [58], the California 
Verbal Learning Test I (CVLT) [59], Symbol Digit Modalities Test (SDMT) [60], and the Trail Making Test $\mathrm{A}+\mathrm{B}(\mathrm{TMT} \mathrm{A}+\mathrm{B})$ [61]. General cognitive performance was evaluated with the Vocabulary Test and Matrix Reasoning subtests of the Wechsler Abbreviated Scale of Intelligence (WASI) [62]. Standardised instructions were followed for all tests. The neuropsychological measures provided 27 variables for the pool of independent measures for the regression analyses.

\subsection{Health status measures}

The study incorporated several health assessment measures to quantify the subjects' current health condition, level of postconcussional complaints and impact of $\mathrm{CHI}$ on performance of everyday tasks. These measures were the SF36 Health Survey (version 2) (SF-36, 8 functional scales and two summary scores) [63], the Rivermead Postconcussion Symptoms Questionnaire (RPSQ, severity of 16 postconcussional symptoms, ranging from zero, i.e., "not experienced at all", to four, i.e., "a severe problem") [64], and the Rivermead Head Injury Follow-up Questionnaire (RHIFQ, specific problems on 10 everyday tasks, rated on a scale from zero, i.e., "no change compared to pre-injury status", to four, i.e., "a severe change compared to pre-injury status") [65]. Summary scores for the RPSQ and the RHIFQ were calculated as the sum of scores on all symptoms or tasks for each questionnaire. Overall, the three health status questionnaires provided 38 variables for the pool of independent measures for the regression analyses.

\subsection{Procedures and statistical analysis}

Patients were assessed within 1 week of injury (mean $5.5 \pm$ 3.0 days) and then at 3 months ( $90 \pm 5.5$ days) and 6 months (182 \pm 15 days). Repeated measures-ANOVA was applied to examine whether the CHI group showed an improvement on the applied health status measures during the first 6 months post-injury. Multiple linear regression was applied to explore the relationship of motor function, neuropsychological performance, or health status in the CHI group at 1 week with health status and outcome at 3 and 6 months post-injury. Separate models were calculated for each outcome measure. Outcome measures were the SF-36 Physical summary, SF-36 Mental summary, summary score on the RPSQ, and summary score on the RHIFQ at 3 and 6 months respectively. The outcome measure was defined as the dependent measure in each case. Independent (predictor) variables were the 1-week measures, these being either the measures of motor performance or neuropsychological function, or the patients' 1-week scores on the SF-36 scales and all items on the Rivermead questionnaires. Stepwise-forward regression analysis was used to generate each model. The ' $F$-to-enter' was 1.0 , the ' $F$-to-remove' 0.5 .

The maximal number of steps (i.e., number of independent variables included in each model) for the 3 and
6 months models was limited to 20 , in order to help preserve the reliability of the resultant estimates. No models were affected by this limitation, as the number of included variables always fell short of 20 (i.e., in each model, there were less than 20 independent variables that made unique and non-redundant contributions of sufficient power to explaining variance in outcome). The relatively high threshold of 20 variables (i.e., high in terms of 'overfitting'-risk based on the present number of cases) was chosen due to the nature of the research question asked. It was not the primary aim of this analysis to create models that could unequivocally describe outcome with a minimal number of key independent variables in every new case of mild CHI but to compare the relative capacity of different functional modalities (i.e., motor, psychometric, selfreported health status) at 1 week to relate to and potentially describe outcome. An important element of the comparison between different modalities is the functional diversity that can be captured. This is indirectly expressed in the number of variables that can make useful and independent contributions to the respective models. This comparison is not possible if the number of in-model variables is too restricted.

The interpretation of the strength of association of each model with the respective dependent variable was based on the adjusted $R^{2}$, which takes into account the number of independent variables and measures the amount of variance in outcome explained by the in-model variables. The relative contribution of each of the respective in-model variables was quantified by standardised regression coefficients (beta).

Normal-probability plots (plotting the residuals versus their expected normal value) calculated for the regression models showed that the residual values in all models were normally distributed. This confirmed that the distribution of variables in these models was sufficiently normal and that the relationships between the dependent and independent variables was appropriately linear, thereby providing a reliable quantification of the relationship between the respective independent measures and each dependent variable.

\section{Results}

\subsection{Recovery of the CHI group on the applied health status (outcome) measures}

The health status of the CHI group improved markedly in the time period between 1 week and 3 and 6 months postinjury. Most of the improvement in health condition was achieved within the first 3 months (Fig. 1). Repeated measures-ANOVA showed that the improvement in health status across the first 6 months was statistically significant on all measures, including the total on the RPSQ $[F(2,72)=$ 20.61, $p<0.00001]$, RHIFQ $[F(2,72)=43.3, p<0.00001]$, the SF-36 Physical summary $[F(2,72)=87.77, p<0.0001]$ and the SF-36 Mental summary $[F(2,72)=16.82, p<$ $0.00001]$. 


\subsection{Association between functional status at 1 week and outcome at 3 months}

Overall motor performance at 1 week post-injury showed much stronger associations with levels of recovery at 3 months than early health status or neuropsychological performance (Table 1). The models based on all measures of motor function (i.e., the combined application of oculomotor and upper-limb visuomotor measures) showed the best relationship with outcome, explaining $85-89 \%$ of the variance in the scores on the applied health assessment measures. In fact, models incorporating exclusively saccadic measures were almost as good and showed only a small reduction in predictive power compared to mixed eye and arm modalities. Conversely, the ability of only upper-limb visuomotor performance at 1 week to explain variance in outcome was much smaller.

The models based on independent variables from all health assessment measures at 1 week (i.e., all SF-36 scales and all items on the Rivermead questionnaires) related to outcome almost as well as the combined eye and arm or the saccade-based models (Table 1). Yet, the relationships between these models and outcome at 3 months were not quite as strong as those observed for the models based on combined motor measures, and overall health status at
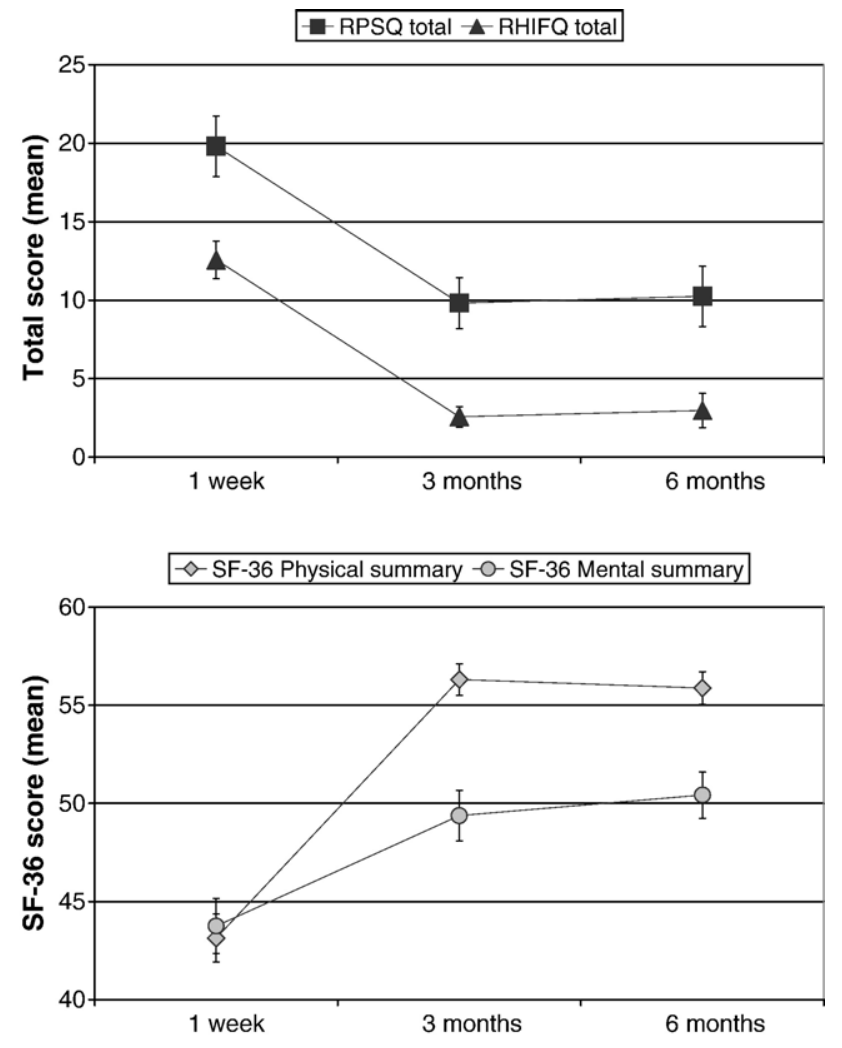

Fig. 1. Improvement on the applied health status measures (dependent 'outcome'-variables in regression analyses) during the first 6 months postinjury (note: low scores on the RPSQ and RHIFQ represent better health status, whereas, on the SF-36, high scores represent better health status). Error bars show standard errors.
1 week post-injury could only account for $54-79 \%$ of the variance in outcome at 3 months.

Neuropsychological status at 1 week showed poor associations with outcome at 3 months (adjusted $R^{2} 13-$ $32 \%$ ) and only a few neuropsychological measures made any useful contributions to the calculated models (Table 1). For the SF-36 Mental Health summary at 3 months, no model with significant associations could be formulated based only on measures of psychometric status at 1 week.

The number of in-model measures in each model roughly equated to predictive performance. There was no consistent prevalence of any specific motor, neuropsychological or health status measures across the respective models (Tables $2 \mathrm{a}$ and $2 \mathrm{~b}$ ) (i.e., no specific measure or clusters of measures within the different modalities showed a universally strong relationship with all outcome measures). Measures of reflexive saccades, antisaccades, memory-guided sequences, and self-paced saccades were found in most models incorporating the contribution of oculomotor measures. These measures covered different motor domains, such as saccadic velocity, latency, accuracy and directional errors. Conversely, measures of oculomotor smooth pursuit featured less frequently. The numbers of in-model measures in the models including only saccadic or only upper-limb visuomotor measures differed considerably from each other, indicating a greater prevalence of eye movement measures able to contribute unique, independent aspects to explaining variance in outcome. The combined models of eye and upper-limb motor measures showed a slightly increased integration of upper-limb visuomotor measures compared to the mono-modal, 'upper-limb-only' models.

In the models based on psychometric status, variables from the WASI, TMT and CVLT were most prevalent. Measures of the PASAT were less common (only present in the model predicting the SF-36 Mental Summary at 3 months), with the SDMT not being represented at all.

The models based on self-reported health status commonly included a number of items from each questionnaire, although the prevalence of variables from certain questionnaires differed slightly depending on the predicted outcome variable.

\subsection{Association between functional status at 1 week and outcome at 6 months}

As observed with outcome at 3 months, motor performance at 1 week post-injury had the strongest relationship with outcome, showing stronger associations with levels of recovery at 6 months than health status or neuropsychological status at 1 week (Table 1$)$.

The models based on a combined selection of oculomotor and upper-limb visuomotor measures showed the best relationship with outcome and could explain $71-85 \%$ of the variance in the scores on the applied health assessment measures. As at 3 months, models incorporating exclusively saccadic measures also showed strong relationships with 
Table 1

Stepwise-forward multiple regression: associations between functional status at 1 week and health status at 3 and 6 months

\begin{tabular}{|c|c|c|c|c|c|c|c|c|c|c|c|c|c|c|c|c|c|}
\hline \multirow[t]{4}{*}{ Independent measure pool } & & \multicolumn{16}{|c|}{ Health assessment measures at 3 and 6 months post-injury (dependent variable) } \\
\hline & & \multicolumn{4}{|c|}{ SF-36 Physical summary } & \multicolumn{4}{|c|}{ SF-36 Mental summary } & \multicolumn{4}{|c|}{ PCS sum (RPSQ total) } & \multicolumn{4}{|c|}{ Everyday tasks (RHIFQ total) } \\
\hline & & \multicolumn{2}{|c|}{3 months } & \multicolumn{2}{|c|}{6 months } & \multicolumn{2}{|c|}{3 months } & \multicolumn{2}{|c|}{6 months } & \multicolumn{2}{|c|}{3 months } & \multicolumn{2}{|c|}{6 months } & \multicolumn{2}{|c|}{3 months } & \multicolumn{2}{|c|}{6 months } \\
\hline & & & $p$-level & & $p$-level & & $p$-level & & $p$-level & & $p$-level & & $p$-level & & $p$-level & & $p$-level \\
\hline Saccades only & $\begin{array}{l}\text { Adjusted } R^{2} \\
\text { Standard error of estimate } \\
\text { Number of qualifying } \\
\text { measures in model }\end{array}$ & $\begin{array}{l}0.78 \\
2.06 \\
14\end{array}$ & $<0.00001$ & $\begin{array}{l}0.70 \\
2.97 \\
10\end{array}$ & 0.00003 & $\begin{array}{l}0.74 \\
3.20 \\
16\end{array}$ & 0.0002 & $\begin{array}{l}0.43 \\
5.51 \\
7\end{array}$ & 0.002 & $\begin{array}{l}0.70 \\
5.44 \\
8\end{array}$ & $<0.00001$ & $\begin{array}{l}0.65 \\
6.45 \\
6\end{array}$ & $<0.00001$ & $\begin{array}{l}0.88 \\
1.46 \\
11\end{array}$ & $<0.00001$ & $\begin{array}{l}0.82 \\
2.72 \\
10\end{array}$ & $<0.00001$ \\
\hline $\begin{array}{l}\text { Upper-limb visuomotor } \\
\text { measures only }\end{array}$ & $\begin{array}{l}\text { Adjusted } R^{2} \\
\text { Standard error of estimate } \\
\text { Number of qualifying } \\
\text { measures in model }\end{array}$ & $\begin{array}{l}0.20 \\
4.35 \\
3\end{array}$ & 0.02 & $\begin{array}{l}0.22 \\
4.48 \\
4\end{array}$ & 0.02 & $\begin{array}{l}0.08 \\
7.42 \\
1\end{array}$ & 0.05 & $\begin{array}{l}0.13 \\
6.66 \\
7\end{array}$ & 0.13 & $\begin{array}{l}0.49 \\
7.09 \\
7\end{array}$ & 0.0003 & $\begin{array}{l}0.20 \\
9.50 \\
5\end{array}$ & 0.03 & $\begin{array}{l}0.63 \\
2.43 \\
5\end{array}$ & $<0.00001$ & $\begin{array}{l}- \\
- \\
0\end{array}$ & $\begin{array}{l}\text { no variables } \\
\text { in model }\end{array}$ \\
\hline $\begin{array}{l}\text { Combined eye and arm } \\
\text { motor measures } \\
\text { (saccades, oculomotor } \\
\text { smooth pursuit, upper-limb) }\end{array}$ & $\begin{array}{l}\text { Adjusted } R^{2} \\
\text { Standard error of estimate } \\
\text { Number of qualifying } \\
\text { measures in model }\end{array}$ & $\begin{array}{l}0.85 \\
1.72 \\
12\end{array}$ & $<0.00001$ & $\begin{array}{l}0.85 \\
2.06 \\
15\end{array}$ & $<0.00001$ & $\begin{array}{l}0.89 \\
2.17 \\
12\end{array}$ & $<0.00001$ & $\begin{array}{l}0.73 \\
3.83 \\
13\end{array}$ & 0.00005 & $\begin{array}{l}0.86 \\
3.83 \\
10\end{array}$ & $<0.00001$ & $\begin{array}{l}0.81 \\
4.80 \\
13\end{array}$ & $<0.00001$ & $\begin{array}{l}0.87 \\
1.56 \\
8\end{array}$ & $<0.00001$ & $\begin{array}{l}0.71 \\
3.33 \\
10\end{array}$ & $<0.00001$ \\
\hline Neuropsychological measures & $\begin{array}{l}\text { Adjusted } R^{2} \\
\text { Standard error of estimate } \\
\text { Number of qualifying } \\
\text { measures in model }\end{array}$ & $\begin{array}{l}0.32 \\
4.07 \\
4\end{array}$ & 0.003 & $\begin{array}{l}0.28 \\
4.38 \\
6\end{array}$ & 0.01 & $\begin{array}{l}0.13 \\
7.32 \\
4\end{array}$ & 0.08 & $\begin{array}{l}0.24 \\
6.31 \\
5\end{array}$ & 0.02 & $\begin{array}{l}0.22 \\
8.73 \\
4\end{array}$ & 0.02 & $\begin{array}{l}0.17 \\
9.55 \\
3\end{array}$ & 0.03 & $\begin{array}{l}0.24 \\
3.42 \\
2\end{array}$ & 0.004 & $\begin{array}{l}0.19 \\
5.46 \\
7\end{array}$ & 0.06 \\
\hline $\begin{array}{l}\text { Health status measures } \\
\quad \text { (all items SF-36, RPSQ, RHIFQ) }\end{array}$ & $\begin{array}{l}\text { Adjusted } R^{2} \\
\text { Standard error of estimate } \\
\text { Number of qualifying } \\
\text { measures in model }\end{array}$ & $\begin{array}{l}0.79 \\
2.25 \\
16\end{array}$ & $<0.00001$ & $\begin{array}{l}0.70 \\
2.78 \\
8\end{array}$ & $<0.00001$ & $\begin{array}{l}0.54 \\
5.24 \\
4\end{array}$ & 0.00001 & $\begin{array}{l}0.69 \\
3.95 \\
9\end{array}$ & $<0.00001$ & $\begin{array}{l}0.70 \\
5.42 \\
8\end{array}$ & $<0.00001$ & $\begin{array}{l}0.68 \\
6.00 \\
8\end{array}$ & $<0.00001$ & $\begin{array}{l}0.75 \\
2.00 \\
14\end{array}$ & $<0.00001$ & $\begin{array}{l}0.76 \\
2.97 \\
10\end{array}$ & $<0.00001$ \\
\hline
\end{tabular}


Table $2 \mathrm{a}$

Stepwise-forward multiple regression (SF-36 at 3 months): in-model measures

\begin{tabular}{|c|c|c|c|c|c|c|}
\hline \multirow{3}{*}{$\begin{array}{l}\text { Independent measure } \\
\text { pool }\end{array}$} & \multicolumn{6}{|c|}{ Health assessment measures at 3 months post-injury (dependent variable) } \\
\hline & \multicolumn{3}{|l|}{ SF-36 Physical summary } & \multicolumn{3}{|l|}{ SF-36 Mental summary } \\
\hline & & Beta & $p$-level & & Beta & $p$-level \\
\hline \multirow[t]{16}{*}{ Saccades only } & Memory-guided sequence amplitude error & 1.04 & 0.0001 & Antisaccades final gain & 2.02 & 0.0000 \\
\hline & Latency of self-paced saccades & -0.86 & 0.0000 & Antisaccades absolute position error & -1.96 & 0.0000 \\
\hline & Peak velocity reflexive saccades $-30^{\circ}$ & -0.79 & 0.0000 & Peak velocity reflexive saccades $-5^{\circ}$ & 1.71 & 0.0000 \\
\hline & Peak velocity reflexive saccades $-20^{\circ}$ & 0.72 & 0.0002 & Peak velocity reflexive saccades $-20^{\circ}$ & 1.35 & 0.0007 \\
\hline & Antisaccades absolute position error & 0.59 & 0.0001 & Peak velocity reflexive saccades $-15^{\circ}$ & -1.32 & 0.0106 \\
\hline & Memory-guided sequence absolute position error & -0.55 & 0.0136 & Peak velocity antisaccades $-15^{\circ}$ & 1.16 & 0.0031 \\
\hline & Antisaccades latency & 0.52 & 0.0001 & Peak velocity reflexive saccades $-30^{\circ}$ & -1.00 & 0.0002 \\
\hline & Reflexive saccades primary gain & -0.45 & 0.0006 & $\begin{array}{l}\text { Correction time directional errors } \\
\text { antisaccade task }\end{array}$ & 0.80 & 0.0001 \\
\hline & Reflexive saccades final gain & 0.43 & 0.0036 & Peak velocity reflexive saccades $-10^{\circ}$ & -0.76 & 0.0183 \\
\hline & Peak velocity reflexive saccades $-25^{\circ}$ & 0.40 & 0.0209 & Reflexive saccades latency & -0.74 & 0.0000 \\
\hline & Directional errors antisaccade task & 0.40 & 0.0014 & Peak velocity antisaccades $-5^{\circ}$ & -0.72 & 0.0559 \\
\hline & Reflexive saccades latency & -0.39 & 0.0030 & Directional errors antisaccade task & -0.69 & 0.0011 \\
\hline & $\begin{array}{l}\text { Directional errors sequence of } \\
\text { memory-guided saccades }\end{array}$ & -0.25 & 0.0350 & Reflexive saccades final gain & -0.60 & 0.0024 \\
\hline & Erroneous prosaccades latency & 0.18 & 0.1267 & Memory-guided sequence primary saccade gain & 0.31 & 0.0187 \\
\hline & & & & Reflexive saccades absolute position error & 0.28 & 0.0334 \\
\hline & & & & Memory-guided sequence absolute time index & 0.26 & 0.0681 \\
\hline \multirow{3}{*}{$\begin{array}{l}\text { Upper-limb visuomotor } \\
\text { function only }\end{array}$} & Upper-limb random preview tracking lag & -1.05 & 0.0016 & Upper-limb movement steadiness & 0.33 & 0.0495 \\
\hline & Upper-limb sine tracking lag & 0.64 & 0.0098 & & & \\
\hline & Upper-limb sine preview tracking lag & 0.57 & 0.0224 & & & \\
\hline \multirow{12}{*}{$\begin{array}{l}\text { Combined eye and arm } \\
\text { motor measures }\end{array}$} & Upper-limb step tracking lag & 1.76 & 0.0002 & Upper-limb random preview tracking lag & -1.67 & 0.0000 \\
\hline & Upper-limb step tracking mean absolute error & -1.59 & 0.0006 & Peak velocity reflexive saccades $-15^{\circ}$ & -1.03 & 0.0000 \\
\hline & Upper-limb sine tracking lag & 0.66 & 0.0000 & $\begin{array}{l}\text { Upper-limb sine tracking mean } \\
\text { absolute error }\end{array}$ & 0.99 & 0.0000 \\
\hline & Upper-limb movement peak velocity & 0.65 & 0.0000 & Upper-limb sine preview tracking lag & 0.97 & 0.0000 \\
\hline & Latency of self-paced saccades & -0.65 & 0.0000 & Upper-limb movement reaction time & 0.73 & 0.0000 \\
\hline & $\begin{array}{l}\text { Upper-limb random preview tracking mean } \\
\text { absolute error }\end{array}$ & -0.65 & 0.0021 & Upper-limb random tracking lag & -0.63 & 0.0001 \\
\hline & Lag $40^{\circ} / \mathrm{s}$ oculomotor smooth pursuit & -0.52 & 0.0000 & Upper-limb sine tracking lag & 0.53 & 0.0001 \\
\hline & Peak velocity reflexive saccades $-30^{\circ}$ & -0.48 & 0.0000 & Antisaccades absolute position error & -0.50 & 0.0000 \\
\hline & $\begin{array}{l}\text { Upper-limb sine preview tracking mean } \\
\text { absolute error }\end{array}$ & 0.38 & 0.0134 & Peak velocity reflexive saccades $-5^{\circ}$ & 0.43 & 0.0017 \\
\hline & Upper-limb movement reaction time & 0.22 & 0.0320 & Peak velocity antisaccades $-5^{\circ}$ & 0.30 & 0.0011 \\
\hline & Peak velocity reflexive saccades $-5^{\circ}$ & 0.19 & 0.0319 & Erroneous prosaccades latency & -0.25 & 0.0042 \\
\hline & Erroneous prosaccades latency & 0.11 & 0.1666 & Lag random oculomotor smooth pursuit & -0.24 & 0.0156 \\
\hline \multirow{4}{*}{$\begin{array}{l}\text { Neuropsychological } \\
\text { measures }\end{array}$} & WASI IQ & 0.66 & 0.0005 & TMT B errors & 0.49 & 0.0244 \\
\hline & CVLT trial 1 & -0.42 & 0.0302 & TMT B time-to-completion & -0.45 & 0.0654 \\
\hline & TMT B errors & 0.25 & 0.0885 & $\operatorname{SDMT}(z)$ & -0.39 & 0.0491 \\
\hline & CVLT serial cluster & -0.24 & 0.1612 & CVLT recall consistency & -0.24 & 0.1382 \\
\hline \multirow[t]{16}{*}{ Health status measures } & Relationship with partner & -0.82 & 0.0002 & Relationship with partner & 0.67 & 0.0001 \\
\hline & Conversation with 1 & -0.67 & 0.0235 & Nausea & -0.57 & 0.0004 \\
\hline & Conversation with 2 or more & 0.62 & 0.0098 & SF-36 mental health & 0.43 & 0.0019 \\
\hline & Enjoying previous leisure activities & 0.56 & 0.0021 & Finding work more tiring & -0.31 & 0.0121 \\
\hline & Coping with family demands & 0.52 & 0.0002 & & & \\
\hline & SF-36 Physical summary & 0.51 & 0.0070 & & & \\
\hline & Double vision & 0.50 & 0.0036 & & & \\
\hline & Feeling frustrated & 0.46 & 0.0050 & & & \\
\hline & SF-36 vitality & -0.42 & 0.0011 & & & \\
\hline & Poor concentration & -0.38 & 0.0088 & & & \\
\hline & Noise sensitivity & -0.37 & 0.0077 & & & \\
\hline & SF-36 bodily pain & 0.35 & 0.0243 & & & \\
\hline & Irritability & -0.34 & 0.0138 & & & \\
\hline & Relationship with previous friends & -0.33 & 0.0481 & & & \\
\hline & SF-36 role emotional & 0.31 & 0.0129 & & & \\
\hline & Routine domestic activities & 0.29 & 0.0486 & & & \\
\hline
\end{tabular}


Table $2 b$

Stepwise-forward multiple regression (Rivermead questionnaires at 3 months): in-model measures

\begin{tabular}{|c|c|c|c|c|c|c|}
\hline \multirow{3}{*}{$\begin{array}{l}\text { Independent measure } \\
\text { pool }\end{array}$} & \multicolumn{6}{|c|}{ Health assessment measures at 3 months post-injury (dependent var.) } \\
\hline & \multicolumn{3}{|l|}{ PCS sum (RPSQ total) } & \multicolumn{3}{|l|}{ Everyday tasks (RHIFQ total) } \\
\hline & & Beta & $p$-level & & Beta & $p$-level \\
\hline \multirow[t]{11}{*}{ Saccades only } & Peak velocity reflexive saccades $-25^{\circ}$ & -0.89 & 0.0000 & Peak velocity reflexive saccades $-20^{\circ}$ & -0.92 & 0.0000 \\
\hline & Memory-guided sequence amplitude error & -0.84 & 0.0054 & Peak velocity reflexive saccades $-15^{\circ}$ & 0.72 & 0.0000 \\
\hline & $\begin{array}{l}\text { Memory-guided sequence amplitude } \\
\text { error primary saccades }\end{array}$ & 0.56 & 0.0036 & Antisaccades latency & -0.69 & 0.0000 \\
\hline & $\begin{array}{l}\text { Memory-guided sequence absolute } \\
\text { position error }\end{array}$ & 0.47 & 0.0484 & Antisaccades final gain & -0.50 & 0.0000 \\
\hline & Peak velocity reflexive saccades $-30^{\circ}$ & 0.45 & 0.0020 & Directional errors antisaccade task & -0.50 & 0.0000 \\
\hline & $\begin{array}{l}\text { Memory-guided sequence primary } \\
\text { saccade gain }\end{array}$ & -0.39 & 0.0042 & $\begin{array}{l}\text { Directional errors sequence of } \\
\text { memory-guided saccades }\end{array}$ & 0.49 & 0.0000 \\
\hline & Latency of self-paced saccades & 0.27 & 0.0292 & Latency of self-paced saccades & 0.42 & 0.0000 \\
\hline & Antisaccades latency & -0.22 & 0.0350 & Peak velocity reflexive saccades $-25^{\circ}$ & -0.31 & 0.0114 \\
\hline & & & & $\begin{array}{l}\text { Memory-guided sequence amplitude } \\
\text { error primary saccades }\end{array}$ & -0.25 & 0.0102 \\
\hline & & & & Peak velocity antisaccades $-5^{\circ}$ & 0.20 & 0.0603 \\
\hline & & & & Erroneous prosaccades latency & 0.19 & 0.0271 \\
\hline \multirow{7}{*}{$\begin{array}{l}\text { Upper-limb } \\
\text { visuomotor } \\
\text { function only }\end{array}$} & Upper-limb random tracking lag & 1.81 & 0.0003 & Upper-limb random preview tracking lag & 1.30 & 0.0000 \\
\hline & Upper-limb step tracking mean absolute error & -1.45 & 0.0399 & Upper-limb sine tracking lag & -1.04 & 0.0000 \\
\hline & Upper-limb random tracking mean absolute error & -1.19 & 0.0193 & Upper-limb sine preview tracking lag & -0.84 & 0.0000 \\
\hline & Upper-limb step tracking lag & 1.10 & 0.0953 & Upper-limb random tracking lag & 0.67 & 0.0009 \\
\hline & Upper-limb sine tracking lag & -0.98 & 0.0001 & Upper-limb step tracking mean absolute error & -0.44 & 0.0017 \\
\hline & Upper-limb sine tracking mean absolute error & 0.85 & 0.0052 & & & \\
\hline & Upper-limb movement peak velocity & -0.31 & 0.0328 & & & \\
\hline \multirow{10}{*}{$\begin{array}{l}\text { Combined eye and arm } \\
\text { motor measures }\end{array}$} & Peak velocity reflexive saccades $-20^{\circ}$ & -0.81 & 0.0000 & Latency of self-paced saccades & 1.15 & 0.0000 \\
\hline & Peak velocity reflexive saccades $-30^{\circ}$ & 0.67 & 0.0000 & Number of self-paced saccades & 0.88 & 0.0000 \\
\hline & Upper-limb random tracking lag & 0.62 & 0.0002 & Antisaccades latency & -0.49 & 0.0000 \\
\hline & $\begin{array}{l}\text { Memory-guided sequence primary } \\
\text { saccade gain }\end{array}$ & -0.57 & 0.0000 & $\begin{array}{l}\text { Directional errors sequence of } \\
\text { memory-guided saccades }\end{array}$ & 0.39 & 0.0002 \\
\hline & Peak velocity reflexive saccades $-25^{\circ}$ & -0.43 & 0.0089 & Peak velocity reflexive saccades $-25^{\circ}$ & -0.39 & 0.0000 \\
\hline & Lag random oculomotor smooth pursuit & 0.36 & 0.0024 & Antisaccades final gain & -0.32 & 0.0009 \\
\hline & Antisaccades latency & -0.31 & 0.0009 & Upper-limb movement peak velocity & -0.24 & 0.0076 \\
\hline & $\begin{array}{l}\text { Upper-limb random preview tracking mean } \\
\text { absolute error }\end{array}$ & -0.29 & 0.0486 & Upper-limb movement reaction time & -0.17 & 0.0487 \\
\hline & Peak velocity of self-paced saccades & 0.28 & 0.0183 & & & \\
\hline & Upper-limb sine tracking mean absolute error & -0.23 & 0.1300 & & & \\
\hline \multirow{4}{*}{$\begin{array}{l}\text { Neuropsychological } \\
\text { measures }\end{array}$} & TMT B time-to-completion & 0.73 & 0.0226 & PASAT 2.4 s pacing $(z)$ & -0.49 & 0.0024 \\
\hline & TMT B errors & -0.62 & 0.0332 & TMT B errors & -0.27 & 0.0825 \\
\hline & TMT A time-to-completion & -0.36 & 0.0688 & & & \\
\hline & CVLT total standard score & -0.34 & 0.0476 & & & \\
\hline \multirow[t]{14}{*}{ Health status measures } & SF-36 Physical summary & 0.63 & 0.0015 & RPSQ total score & -2.78 & 0.0000 \\
\hline & SF-36 bodily pain & -0.56 & 0.0011 & Dizziness & 0.99 & 0.0000 \\
\hline & SF-36 physical function & -0.42 & 0.0058 & SF-36 physical function & -0.92 & 0.0000 \\
\hline & Coping with family demands & -0.39 & 0.0015 & Blurred vision & 0.70 & 0.0001 \\
\hline & Relationship with previous friends & 0.36 & 0.0061 & Restlessness & 0.69 & 0.0001 \\
\hline & SF-36 general health & -0.34 & 0.0052 & Irritability & 0.66 & 0.0004 \\
\hline & Enjoying previous leisure activities & -0.32 & 0.0083 & Routine domestic activities & -0.58 & 0.0001 \\
\hline & Restlessness & 0.30 & 0.0072 & Noise sensitivity & 0.53 & 0.0127 \\
\hline & & & & Poor memory & 0.47 & 0.0026 \\
\hline & & & & SF-36 role physical & 0.43 & 0.0011 \\
\hline & & & & Poor concentration & 0.42 & 0.0402 \\
\hline & & & & Coping with family demands & -0.38 & 0.0018 \\
\hline & & & & SF-36 bodily pain & -0.38 & 0.0069 \\
\hline & & & & Headaches & 0.35 & 0.0127 \\
\hline
\end{tabular}


Table 3a

Stepwise-forward multiple regression (SF-36 at 6 months): in-model measures

\begin{tabular}{|c|c|c|c|c|c|c|}
\hline \multirow{3}{*}{$\begin{array}{l}\text { Independent } \\
\text { measure pool }\end{array}$} & \multicolumn{6}{|c|}{ Health assessment measures at 6 months post-injury (dependent var.) } \\
\hline & \multicolumn{3}{|l|}{ SF-36 Physical summary } & \multicolumn{3}{|l|}{ SF-36 Mental summary } \\
\hline & & Beta & $p$-level & & Beta & $p$-level \\
\hline \multirow[t]{10}{*}{ Saccades only } & Peak velocity reflexive saccades $-30^{\circ}$ & -1.25 & 0.0000 & Peak velocity reflexive saccades $-20^{\circ}$ & 0.84 & 0.0086 \\
\hline & Peak velocity reflexive saccades $-25^{\circ}$ & 0.85 & 0.0009 & Peak velocity reflexive saccades $-15^{\circ}$ & -0.74 & 0.0339 \\
\hline & Peak velocity reflexive saccades $-20^{\circ}$ & 0.76 & 0.0022 & Latency of self-paced saccades & -0.60 & 0.0008 \\
\hline & Correction time directional errors antisaccade task & 0.64 & 0.0000 & $\begin{array}{l}\text { Directional errors sequence of } \\
\text { memory-guided saccades }\end{array}$ & 0.54 & 0.0040 \\
\hline & Memory-guided sequence primary saccade gain & 0.41 & 0.0015 & Peak velocity reflexive saccades $-30^{\circ}$ & -0.52 & 0.0226 \\
\hline & Antisaccades primary gain & 0.40 & 0.0169 & Peak velocity antisaccades $-15^{\circ}$ & 0.33 & 0.0513 \\
\hline & Reflexive saccades latency & -0.33 & 0.0124 & Reflexive saccades primary gain & 0.25 & 0.1740 \\
\hline & Peak velocity reflexive saccades $-5^{\circ}$ & -0.32 & 0.0263 & & & \\
\hline & Reflexive saccades final gain & 0.28 & 0.0660 & & & \\
\hline & Number of self-paced saccades & 0.26 & 0.0582 & & & \\
\hline \multirow{7}{*}{$\begin{array}{l}\text { Upper-limb } \\
\text { visuomotor } \\
\text { function only }\end{array}$} & Upper-limb random preview tracking lag & -1.15 & 0.0011 & Upper-limb random tracking lag & -1.54 & 0.0148 \\
\hline & Upper-limb sine preview tracking lag & 0.62 & 0.0158 & Upper-limb random tracking mean absolute error & 1.44 & 0.0355 \\
\hline & Upper-limb sine tracking lag & 0.52 & 0.0304 & Upper-limb sine tracking lag & 0.63 & 0.0412 \\
\hline & Upper-limb step tracking mean absolute error & 0.36 & 0.0410 & $\begin{array}{l}\text { Upper-limb sine preview tracking mean } \\
\text { absolute error }\end{array}$ & 0.52 & 0.0383 \\
\hline & & & & Upper-limb random preview tracking lag & -0.46 & 0.1255 \\
\hline & & & & Upper-limb sine tracking mean absolute error & -0.40 & 0.2586 \\
\hline & & & & Upper-limb movement peak velocity & 0.25 & 0.1698 \\
\hline \multirow{15}{*}{$\begin{array}{l}\text { Combined eye } \\
\text { and arm motor } \\
\text { measures }\end{array}$} & Number of self-paced saccades & 1.54 & 0.0000 & Latency of self-paced saccades & -1.10 & 0.0009 \\
\hline & Peak velocity reflexive saccades $-30^{\circ}$ & -1.33 & 0.0000 & Peak velocity reflexive saccades $-20^{\circ}$ & 1.00 & 0.0002 \\
\hline & Upper-limb step tracking lag & 1.31 & 0.0086 & Number of self-paced saccades & -0.94 & 0.0032 \\
\hline & Latency of self-paced saccades & 1.25 & 0.0002 & Peak velocity reflexive saccades $-30^{\circ}$ & -0.82 & 0.0001 \\
\hline & Upper-limb step tracking mean absolute error & -1.24 & 0.0156 & Upper-limb random tracking lag & -0.80 & 0.0004 \\
\hline & Peak velocity reflexive saccades $-25^{\circ}$ & 1.22 & 0.0000 & Upper-limb sine tracking mean absolute error & 0.70 & 0.0004 \\
\hline & Correction time directional errors antisaccade task & 0.75 & 0.0002 & Peak velocity reflexive saccades $-25^{\circ}$ & -0.68 & 0.0073 \\
\hline & Lag $40^{\circ} / \mathrm{s}$ oculomotor smooth pursuit & -0.62 & 0.0000 & Lag random oculomotor smooth pursuit & -0.49 & 0.0009 \\
\hline & Upper-limb sine preview tracking lag & 0.48 & 0.0017 & $\begin{array}{l}\text { Directional errors sequence of } \\
\text { memory-guided saccades }\end{array}$ & 0.43 & 0.0043 \\
\hline & $\begin{array}{l}60 \% \text { s sinusoidal smooth pursuit average } \\
\text { peak velocity }\end{array}$ & 0.47 & 0.0036 & Directional errors antisaccade task & -0.41 & 0.0059 \\
\hline & Erroneous prosaccades latency & -0.30 & 0.0540 & Memory-guided sequence primary saccade gain & 0.41 & 0.0045 \\
\hline & Memory-guided sequence primary saccade gain & 0.28 & 0.0091 & Peak velocity antisaccades $-15^{\circ}$ & 0.36 & 0.0183 \\
\hline & Upper-limb movement steadiness & 0.24 & 0.0134 & $\begin{array}{l}40 \% \text { s sinusoidal smooth pursuit average } \\
\text { peak velocity }\end{array}$ & -0.20 & 0.1134 \\
\hline & Directional errors antisaccade task & 0.21 & 0.0500 & & & \\
\hline & Antisaccades latency & 0.15 & 0.2371 & & & \\
\hline \multirow{6}{*}{$\begin{array}{l}\text { Neuropsychological } \\
\text { measures }\end{array}$} & CVLT trial 1 & -0.71 & 0.0050 & PASAT $1.6 \mathrm{~s}$ pacing $(z)$ & -0.72 & 0.0077 \\
\hline & CVLT total standard score & 0.70 & 0.0322 & CVLT trial 1 & 0.64 & 0.0052 \\
\hline & WASI Verbal T & 0.49 & 0.0154 & PASAT $1.2 \mathrm{~s}$ pacing $(z)$ & 0.53 & 0.0485 \\
\hline & CVLT recall consistency & -0.36 & 0.0816 & CVLT serial cluster & 0.51 & 0.0208 \\
\hline & CVLT recall discriminability & -0.32 & 0.0564 & CVLT list B & -0.44 & 0.0235 \\
\hline & TMT B errors & 0.27 & 0.0826 & & & \\
\hline \multirow{9}{*}{$\begin{array}{l}\text { Health status } \\
\text { measures }\end{array}$} & Relationship with previous friends & -0.69 & 0.0000 & Feeling depressed & 0.59 & 0.0011 \\
\hline & Relationship with partner & -0.56 & 0.0000 & Noise sensitivity & -0.57 & 0.0001 \\
\hline & Enjoying previous leisure activities & 0.47 & 0.0032 & SF-36 mental summary & 0.52 & 0.0031 \\
\hline & Conversation with 2 or more & 0.47 & 0.0003 & SF-36 mental health & 0.45 & 0.0120 \\
\hline & Sleep disturbance & -0.46 & 0.0000 & Enjoying previous leisure activities & -0.40 & 0.0081 \\
\hline & Routine domestic activities & -0.38 & 0.0069 & Double vision & 0.38 & 0.0070 \\
\hline & SF-36 role physical & 0.31 & 0.0068 & Routine domestic activities & 0.31 & 0.0265 \\
\hline & Coping with family demands & 0.26 & 0.0354 & Feeling frustrated & -0.28 & 0.0289 \\
\hline & & & & Dizziness & 0.26 & 0.0437 \\
\hline
\end{tabular}


Table 3b

Stepwise-forward multiple regression (Rivermead questionnaires at 6 months): in-model measures

\begin{tabular}{|c|c|c|c|c|c|c|}
\hline \multirow{3}{*}{$\begin{array}{l}\text { Independent } \\
\text { measure pool }\end{array}$} & \multicolumn{6}{|c|}{ Health assessment measures at 6 months post-injury (dependent var.) } \\
\hline & \multicolumn{3}{|l|}{ PCS sum (RPSQ total) } & \multicolumn{3}{|l|}{ Everyday tasks (RHIFQ total) } \\
\hline & & Beta & $p$-level & & Beta & $p$-level \\
\hline \multirow[t]{10}{*}{ Saccades only } & Peak velocity reflexive saccades $-30^{\circ}$ & 1.10 & 0.0000 & Peak velocity reflexive saccades $-20^{\circ}$ & -1.28 & 0.0000 \\
\hline & Peak velocity reflexive saccades $-20^{\circ}$ & -1.02 & 0.0001 & Peak velocity reflexive saccades $-30^{\circ}$ & 1.04 & 0.0000 \\
\hline & Peak velocity reflexive saccades $-25^{\circ}$ & -0.60 & 0.0074 & Memory-guided sequence primary saccade gain & -0.65 & 0.0002 \\
\hline & $\begin{array}{l}\text { Memory-guided sequence primary saccade } \\
\text { gain }\end{array}$ & -0.46 & 0.0006 & Peak velocity reflexive saccades $-10^{\circ}$ & 0.48 & 0.0005 \\
\hline & Peak velocity reflexive saccades $-10^{\circ}$ & 0.40 & 0.0165 & Antisaccades final gain & -0.40 & 0.0008 \\
\hline & Correction time directional errors antisaccade task & -0.29 & 0.0344 & Correction time directional errors antisaccade task & -0.36 & 0.0013 \\
\hline & & & & Peak velocity reflexive saccades $-25^{\circ}$ & -0.34 & 0.0464 \\
\hline & & & & Memory-guided sequence final saccade gain & 0.34 & 0.0278 \\
\hline & & & & Number of self-paced saccades & -0.29 & 0.0042 \\
\hline & & & & Memory-guided sequence absolute time index & 0.27 & 0.0064 \\
\hline \multirow{5}{*}{$\begin{array}{l}\text { Upper-limb } \\
\text { visuomotor } \\
\text { function only }\end{array}$} & $\begin{array}{l}\text { Upper-limb random preview tracking mean } \\
\text { absolute error }\end{array}$ & 0.63 & 0.0150 & No variables in model & & \\
\hline & Upper-limb sine preview tracking lag & -0.59 & 0.0038 & & & \\
\hline & Upper-limb sine tracking lag & -0.42 & 0.0546 & & & \\
\hline & Upper-limb movement peak velocity & -0.33 & 0.0523 & & & \\
\hline & Upper-limb step tracking lag & -0.33 & 0.0670 & & & \\
\hline \multirow{13}{*}{$\begin{array}{l}\text { Combined eye } \\
\text { and arm } \\
\text { motor measures }\end{array}$} & Peak velocity reflexive saccades $-10^{\circ}$ & 0.83 & 0.0000 & Memory-guided sequence absolute time index & 0.74 & 0.0000 \\
\hline & Upper-limb movement reaction time & -0.81 & 0.0000 & Peak velocity reflexive saccades $-10^{\circ}$ & 0.72 & 0.0002 \\
\hline & Peak velocity reflexive saccades $-25^{\circ}$ & -0.66 & 0.0009 & Peak velocity reflexive saccades $-25^{\circ}$ & -0.62 & 0.0004 \\
\hline & Antisaccades absolute position error & 0.50 & 0.0001 & Upper-limb movement reaction time & -0.58 & 0.0001 \\
\hline & Memory-guided sequence absolute time index & 0.44 & 0.0005 & Peak velocity of self-paced saccades & -0.42 & 0.0308 \\
\hline & Lag random oculomotor smooth pursuit & 0.42 & 0.0043 & Peak velocity reflexive saccades $-30^{\circ}$ & 0.42 & 0.0063 \\
\hline & Latency of self-paced saccades & 0.39 & 0.0013 & $\begin{array}{l}\text { Memory-guided sequence amplitude error } \\
\text { primary saccades }\end{array}$ & 0.41 & 0.0022 \\
\hline & Peak velocity antisaccades $-5^{\circ}$ & -0.36 & 0.0023 & $\begin{array}{l}60^{\circ} / \mathrm{s} \text { sinusoidal smooth pursuit average } \\
\text { peak velocity }\end{array}$ & -0.27 & 0.0196 \\
\hline & Peak velocity reflexive saccades $-30^{\circ}$ & 0.36 & 0.0397 & Lag $40^{\circ} / \mathrm{s}$ oculomotor smooth pursuit & 0.25 & 0.0247 \\
\hline & Correction time directional errors antisaccade task & -0.31 & 0.0133 & Reflexive saccades final gain & -0.15 & 0.2421 \\
\hline & Reflexive saccades latency & -0.29 & 0.0165 & & & \\
\hline & $\begin{array}{l}40^{\circ} / \mathrm{s} \text { sinusoidal smooth pursuit average } \\
\text { peak velocity }\end{array}$ & 0.20 & 0.0692 & & & \\
\hline & Upper-limb step tracking mean absolute error & -0.15 & 0.1567 & & & \\
\hline \multirow{7}{*}{$\begin{array}{l}\text { Neuropsychological } \\
\text { measures }\end{array}$} & WASI IQ & 4.75 & 0.0223 & TMT B time-to-completion & 0.63 & 0.0699 \\
\hline & WASI Verbal T & -3.64 & 0.0119 & CVLT trial 5 & -0.58 & 0.0280 \\
\hline & WASI Matrix T & -1.77 & 0.0474 & CVLT long delay free recall & 0.54 & 0.0412 \\
\hline & & & & WASI Verbal $\mathrm{T}$ & -0.51 & 0.0198 \\
\hline & & & & TMT B errors & -0.48 & 0.1208 \\
\hline & & & & TMT A time-to-completion & -0.42 & 0.0536 \\
\hline & & & & CVLT trial 1 & 0.39 & 0.0679 \\
\hline \multirow{10}{*}{$\begin{array}{l}\text { Health status } \\
\text { measures }\end{array}$} & Enjoying previous leisure activities & -0.57 & 0.0004 & Conversation with 2 or more & -0.85 & 0.0002 \\
\hline & Participating in previous social activity & 0.43 & 0.0045 & RPSQ total score & -0.66 & 0.0214 \\
\hline & Relationship with previous friends & 0.36 & 0.0040 & Conversation with 1 & 0.64 & 0.0054 \\
\hline & Sleep disturbance & 0.33 & 0.0031 & Slowed thinking & 0.62 & 0.0015 \\
\hline & Coping with family demands & -0.30 & 0.0208 & Light sensitivity & 0.54 & 0.0020 \\
\hline & SF-36 general health & -0.30 & 0.0125 & Nausea & 0.45 & 0.0023 \\
\hline & Relationship with partner & 0.29 & 0.0252 & Relationship with previous friends & 0.43 & 0.0017 \\
\hline & SF-36 mental health & -0.28 & 0.0211 & Sleep disturbance & 0.37 & 0.0008 \\
\hline & & & & Blurred vision & -0.33 & 0.0240 \\
\hline & & & & SF-36 mental health & -0.31 & 0.0121 \\
\hline
\end{tabular}

outcome at 6 months (adjusted $R^{2} 43-82 \%$ ) (Table 1), although their power to predict 6-month outcome was generally not as high as that observed for the 3-month outcomes.
The ability of upper-limb visuomotor function to predict outcome at 6 months was substantially smaller than that of measures of oculomotor function. The corresponding models 
incorporated only a few measures and no relationship was seen between upper-limb visuomotor function at 1 week and problems on everyday tasks as reported on the RHIFQ at 6 months. However, the combined use of oculomotor and upper-limb measures identified independent contributions from upper-limb visuomotor function for predicting problems on everyday tasks and other outcome measures, this being evident from the integration of upper-limb measures into the combined models, even for the RHIFQ (Tables 3a and $3 b)$.

The models based on independent variables from all health assessment measures at 1 week (i.e., all SF-36 scales and all items on the Rivermead questionnaires) were weaker than the models based on combined eye and arm motor function (Table 1), with early post-injury health status explaining $68-76 \%$ of the variance in outcome.

Psychometric status at 1 week did not usefully explain variance in 6-month outcomes. Neuropsychological performance as assessed by the neuropsychological tests deployed in this study could account for only $17-28 \%$ of the variance in the applied outcome measures.

The motor-based models continued to include measures from different tasks and functional domains, such as movement velocity, latency, motor accuracy and directional errors of antisaccades and memory-guided sequences (Tables 3a and $3 b)$.

Each model based on the combined application of the SF36 scales and items from both Rivermead questionnaires incorporated measures from all questionnaires. However, as observed in the motor-based models, the pattern of independent measures and strength of their contribution to the respective models varied according to the dependent variable, and no specific measure showed a consistently strong relationship with all outcome measures (Tables $3 a$ and $3 b$ ).

Models based on neuropsychological measures tended to incorporate a higher number of independent measures than observed in the 3-month models but were generally weaker in their predictions.

\section{Discussion}

The present study indicates a close association between early motor function and levels of recovery and outcome at 3 and 6 months after mild CHI. Motor performance at 1 week related closely to outcome as assessed by the scores on the SF-36 summary scales and each of the Rivermead questionnaires at 3 and 6 months post-injury. Across all regression analyses, the models based on combined eye and arm motor functions consistently showed the strongest associations with outcome measures. This effect of a relative advantage of motor function in relation to outcome was present both at 3 and 6 months. These findings suggest that post-injury motor function, and in particular eye movement performance, may have potential in providing useful indications of outcome, and that early assessment of eye and arm motor function may contribute to a prospective quantification of functional re- covery at 3 and 6 months following mild $\mathrm{CHI}$, independently of measures of patient self-report and assessment of psychometric status.

The models based on the combined measure pool of SF36 scales and all scores on postconcussional symptoms and complaints on the two Rivermead questionnaires at 1 week produced models with predictive power that was slightly weaker than that of models based on motor function. The association of the 'symptom/complaint'-based models with outcome was, however, reasonably strong, and much stronger than that of the models based on psychometric status. This indicates that quantification of early postconcussional symptoms and measures of performance on everyday tasks may be preferable to neuropsychological assessment in providing prospective indications of recovery after mild CHI. The finding of associations between the self-reported health status at 1 week and level of recovery at 3 and 6 months post-injury appears to be largely consistent with earlier evidence of an association between early symptomatic complaints and outcome [4,16-18,21,53], although the strength of these associations is variable across studies.

The poor ability of models based on psychometric status (i.e., the pool of 27 measures derived from PASAT, SDMT, CVLT, TMT A and B, and WASI) at 1 week to relate to and predict outcome in the current study may be due to multiple reasons. It was apparent that the neuropsychological tests applied in our study were unable to produce a sufficient number of measures showing significant correlations with outcome at 3 and 6 months, providing unique non-redundant contributions to the respective models. It is possible that this may have been due to the specific selection and limited number of neuropsychological tests. However, all of the tests applied in our study are known to be sensitive to mild head trauma and have been used in numerous other studies to measure attention, short-term, working and episodic/declarative memory, speed of information processing, general cognitive and 'executive' function after mild CHI. Yet, performance on the applied tests incorporates elements of most of these functions, and, therefore, the resulting measures may have been, due to this overlap, too closely related and lacking the diversity needed to provide a sufficient number of measures making unique contributions to the respective models. However, results from earlier studies $[7,15,29,53,66]$ suggest that the use of other neuropsychological tests is not likely to improve the predictive power of neuropsychological assessment.

A crucial factor contributing to the low ability of the psychometric models to relate to outcome may have been the susceptibility of neuropsychological testing to pre-morbid factors such as compensatory abilities, intelligence, educational background, and sociodemographic factors such as employment or socioeconomic status [25,29,40-43,67], resulting in inconsistent relationships between the initial injury severity and the extent of cognitive impairment. This inconsistency is likely to distort the relationship between head-trauma-related cerebral dysfunction and the reflection 
of such dysfunction in the neuropsychological test results $[40,67]$. The dissociation between neuropsychological assessment and the presence of cerebral dysfunction resulting from this distortion is likely to adversely affect the capacity of psychometric assessment to project on outcome.

The higher number of in-model variables in the models based exclusively on saccades compared to the upper-limb models, indicates less redundancy amongst the measures of oculomotor (saccadic) function, and that the eye movement measures were able to make more independent contributions to outcome prediction. In turn, this suggests that the assessment of eye movement function may provide measures able to detect a wider spectrum of independent nuances in brain function than the upper-limb tracking tasks.

Interestingly, the motor-based regression models repeatedly showed contributions of motor measures representing subconscious low-level motor functions (e.g., saccadic velocities, measures of oculomotor smooth pursuit and ballistic upper-limb movement peak velocity). These functions represent basic accessory elements of the functional mainframe underlying cerebral motor output and are mediated by deeper subcortical structures, brainstem, and cerebellum [68-71]. Consistent with the centripetal model of neural dysfunction in CHI $[49,72]$ and evidence of an association between persistent postconcussional complaints and subcortical dysfunction after mild CHI $[35,73,74]$, MRI evidence has shown that the depth of parenchymal lesions is directly related to the severity and duration of LOC and that the depth of lesion is predictive of the recovery level on the Glasgow Outcome Scale at 6 months post-injury [75]. Consequently, it is an intriguing finding of this study that motor measures assessing the function of 'deeper' brain structures, the functional integrity of which is a factor in deciding outcome, are indeed associated with level of recovery. In all motor-based models, these 'subconscious' motor functions featured alongside motor functions that are more influenced by aspects of volitional control (e.g., directional errors, latencies, motor accuracy), primarily mediated by frontal, prefrontal, parietal and temporal cortical motor areas $[46,47,68,76]$. Due to the complex functional neuroanatomy employed for eye and arm motor processing, motor testing is able to simultaneously sample cortical and subcortical brain function. Taking into account the composition of motor measures in the motor-based regression models, the current results indicate that it is possible to integrate the functional 'make-up' resulting from this sampling process into a model able to describe key aspects of both cortical and subcortical function and relate the corresponding motor performance at 1 week to levels of recovery in the months post-injury.

Our current findings suggest that measures of subconscious and subcortical functioning may be an important element in obtaining a complete picture of the functional integrity of the brain after mild CHI and their inclusion in outcome prediction may be crucial in providing accurate projections on recovery after head trauma. Appropriately,
$50 \%$ of the models based on early health status featured nausea or dizziness, symptoms which might imply involvement of structures caudal to the grey and white matter junction. Similarly, De Kruijk et al. [16] found the presence of headaches, nausea and dizziness early after mild CHI to be indicative of the presence of postconcussional symptoms 6 months later, this being consistent with the results of other studies showing the association between the early presence and degree of these symptoms and later levels of recovery throughout the first year after mild CHI $[4,17,18,21]$.

Given the strength of the associations between early motor assessment and outcome that emerged in the current mild CHI group, it is likely that our findings describe an effect which is present in the majority of mild CHI patients. It has to be kept in mind, however, that the current models were based on a limited sample size of 37 patients. While this sample size was sufficient to examine deficits in eye and arm motor function during the first year post-injury [45] and compare the association of different functional modalities at 1 week with later outcome, it may be insufficient to support an expectation that the principle of a motor-based outcome prediction will be applicable to the general mild CHI population. Validation of the current models and the relationships between early motor function and outcome in a larger cohort of mild CHI patients is essential before any clinical use of this method can be considered. If future studies confirm the utility of instrumented motor assessment as applied in the present study to predict outcome after mild head trauma, it should be possible to develop a clinical application of this method via a portable laptop-based test instrument making use of compact, video-based eye trackers already commercially available. Instrumented oculomotor assessment has the best potential for the development of a portable and easy-touse test-kit based on commercially available equipment, and would involve only a small reduction in predictive power compared to an instrument based upon both eye and arm motor measures. Any clinical application of such testing will have to be computerised and fully automated, ready to be used by clinical staff. Preliminary assessments by our group have confirmed the technical feasibility of such a computerised clinical test-kit.

In conclusion, our current findings indicate a strong association of early post-injury motor function with health status and level of recovery during the first 6 months after mild CHI. Instrumented motor testing may provide an objective, quantitative assessment able to improve prediction of outcome while having the advantage of being entirely independent from patient self-report. This, in turn, may benefit patients with mild $\mathrm{CHI}$ and help to reduce long-term morbidity resulting from mild head trauma due to the better targeting of early health care intervention.

\section{Acknowledgements}

The study was hosted by the Canterbury District Health Board and the Christchurch School of Medicine and Health 
Sciences, University of Otago, New Zealand. Funding for patients' travel costs was provided by the Neurological Foundation of New Zealand (NFNZ grant number 0027/ SPG). We would like to thank these institutions for their support of this research.

\section{References}

[1] Jennett B. Epidemiology of head injury. J Neurol Neurosurg Psychiatry 1996;60:362-9.

[2] Kraus JF, Nourjah P. The epidemiology of mild head injury. In: Levin HS, Eisenberg HM, Benton AL, editors. Mild Head Injury. New York: Oxford University Press; 1989. p. 8-22.

[3] Dikmen SS, Temkin N, Armsden G. Neuropsychological recovery: relationship to psychosocial functioning and postconcussional complaints. In: Levin HS, Eisenberg HM, Benton AL, editors. Mild Head Injury. New York: Oxford University Press; 1989. p. 229-41.

[4] Rutherford WH. Postconcussion symptoms: relationship to acute neurological indices, individual differences, and circumstances of injury. In: Levin HS, Eisenberg HM, Benton AL, editors. Mild Head Injury. New York: Oxford University Press; 1989. p. 217-28.

[5] Evans RW. The postconcussion syndrome and the sequelae of mild head injury. Neurol Clin 1992;10:815-47.

[6] Bohnen N, Jolles J. Neurobehavioral aspects of postconcussive symptoms after mild head injury. J Nerv Ment Dis 1992;180:683-92.

[7] King NS. Emotional, neuropsychological, and organic factors: their use in the prediction of persisting postconcussion symptoms after moderate and mild head injuries. J Neurol Neurosurg Psychiatry 1996;61:75-81.

[8] Alexander MP. Mild traumatic brain injury: pathophysiology, natural history, and clinical management. Neurology 1995;45:1253-60.

[9] van der Naalt J, van Zomeren AH, Sluiter WJ, Minderhoud JM. One year outcome in mild to moderate head injury: the predictive value of acute injury characteristics related to complaints and return to work. J Neurol Neurosurg Psychiatry 1999;66:207-13.

[10] Rimel RW, Giordani B, Barth JT, Boll TJ, Jane JA. Disability caused by minor head injury. Neurosurgery 1981;9:221-8.

[11] Mallinson AI, Longridge NS. Specific vocalized complaints in whiplash and minor head injury patients. Am J Otol 1998;19:809-13.

[12] Wrightson P, Gronwall D. Mild head injury in New Zealand: incidence of injury and persisting symptoms. NZ Med J 1998;111:99-101.

[13] Emanuelson I, Andersson Holmkvist E, Bjorklund R, Stalhammar D. Quality of life and post-concussion symptoms in adults after mild traumatic brain injury: a population-based study in western Sweden. Acta Neurol Scand 2003;108:332-8.

[14] Stalnacke BM, Bjornstig U, Karlsson K, Sojka P. One-year follow-up of mild traumatic brain injury: post-concussion symptoms, disabilities and life satisfaction in relation to serum levels of S-100B and neuronespecific enolase in acute phase. J Rehabil Med 2005;37:300-5.

[15] Bazarian JJ, Wong T, Harris M, Leahey N, Mookerjee S, et al. Epidemiology and predictors of post-concussive syndrome after minor head injury in an emergency population. Brain Inj 1999;13: $173-89$.

[16] De Kruijk JR, Leffers P, Menheere PPCA, Meerhoff S, Rutten J, et al. Prediction of post-traumatic complaints after mild traumatic brain injury: early symptoms and biochemical markers. J Neurol Neurosurg Psychiatry 2002;73:727-32.

[17] Thornhill S, Teasdale GM, Murray GD, McEwen J, Roy CW, et al. Disability in young people and adults one year after head injury: prospective cohort study. Br Med J 2000;320:1631-5.

[18] Middelboe T, Andersen HS, Birket-Smith M, Friis ML. Minor head injury: impact on general health after 1 year. A prospective follow-up study. Acta Neurol Scand 1992;85:5-9.

[19] Centers for Disease Control and Prevention, National Center for Injury Prevention and Control. Traumatic Brain Injury in the United States-
A Report to Congress. Atlanta, GA: Centers for Disease Control and Prevention; 1999.

[20] Mittenberg W, Canyock EM, Condit D, Patton C. Treatment of postconcussion syndrome following mild head injury. J Clin Exp Neuropsychol 2001;23:829-36.

[21] Savola O, Hillbom M. Early predictors of post-concussion symptoms in patients with mild head injury. Eur J Neurol 2003;10:175-81.

[22] Dikmen S, McLean A, Temkin N. Neuropsychological and psychosocial consequences of minor head injury. J Neurol Neurosurg Psychiatry 1986;49:1227-32.

[23] Max W, MacKenzie EJ, Rice DP. Head injuries: costs and consequences. J Head Trauma Rehabil 1991;6:76-91.

[24] Balestreri M, Czosnyka M, Chatfield DA, Steiner LA, Schmidt EA, et al. Predictive value of Glasgow Coma Scale after brain trauma: change in trend over the past ten years. J Neurol Neurosurg Psychiatry 2004;75:161-2.

[25] Wallesch CW, Curio N, Kutz S, Jost S, Bartels C, et al. Outcome after mild-to-moderate blunt head injury: effects of focal lesions and diffuse axonal injury. Brain Inj 2001;15:401-12.

[26] Wenden FJ, Crawford S, Wade DT, King NS, Moss NE. Assault, posttraumatic amnesia and other variables related to outcome following head injury. Clin Rehabil 1998;12:53-63.

[27] van der Naalt J. Prediction of outcome in mild to moderate head injury: a review. J Clin Exp Neuropsychol 2001;23:837-51.

[28] Ingebrigtsen T, Waterloo K, Marup-Jensen S, Attner E, Romner B. Quantification of post-concussion symptoms 3 months after minor head injury in 100 consecutive patients. J Neurol 1998;245: 609-12.

[29] Ponsford J, Willmott C, Rothwell A, Cameron P, Kelly AM, et al. Factors influencing outcome following mild traumatic brain injury in adults. J Int Neuropsychol Soc 2000;6:568-79.

[30] Ingebrigtsen T, Romner B. Biochemical serum markers for brain damage: a short review with emphasis on clinical utility in mild head injury. Restor Neurol Neurosci 2003;21:171-6.

[31] Ingebrigtsen T, Waterloo K, Jacobsen EA, Langbakk B, Romner B. Traumatic brain damage in minor head injury: relation of serum S-100 protein measurements to magnetic resonance imaging and neurobehavioral outcome. Neurosurgery 1999;45:468-75 [discussion 475-6].

[32] Ingebrigtsen T, Romner B, Marup-Jensen S, Dons M, Lundqvist C, et al. The clinical value of serum S-100 protein measurements in minor head injury: a Scandinavian multicentre study. Brain Inj 2000;14: 1047-55.

[33] Levin HS, Williams DH, Eisenberg HM, High Jr WM, Guinto Jr FC. Serial MRI and neurobehavioural findings after mild to moderate closed head injury. J Neurol Neurosurg Psychiatry 1992;55:255-62.

[34] Umile EM, Plotkin RC, Sandel ME. Functional assessment of mild traumatic brain injury using SPECT and neuropsychological testing. Brain Inj 1998;12:577-94.

[35] Hofman PA, Verhey FR, Wilmink JT, Rozendaal N, Jolles J. Brain lesions in patients visiting a memory clinic with postconcussional sequelae after mild to moderate brain injury. J Neuropsychiatry Clin Neurosci 2002;14:176-84.

[36] Radanov BP, Bicik I, Dvorak J, Antinnes J, von Schulthess GK, et al. Relation between neuropsychological and neuroimaging findings in patients with late whiplash syndrome. J Neurol Neurosurg Psychiatry 1999;66:485-9.

[37] Schatz P, Pardini JE, Lovell MR, Collins MW, Podell K. Sensitivity and specificity of the ImPACT Test Battery for concussion in athletes. Arch Clin Neuropsychol 2006;21:91-9.

[38] Iverson GL, Brooks BL, Collins MW, Lovell MR. Tracking neuropsychological recovery following concussion in sport. Brain Inj 2006;20:245-52.

[39] Lovell MR, Getz GE. The ImPACT Neuropsychological Test Battery. In: Echemendia RJ, editor. Sports neuropsychology: assessment and management of traumatic brain injury. New York, NY, USA: Guilford Press; 2006. p. 193-215.

[40] Binder LM, Rohling ML, Larrabee J. A review of mild head trauma. Part I: Meta-analytic review of neuropsychological studies. J Clin Exp Neuropsychol 1997;19:421-31. 
[41] Reitan RM, Wolfson D. The influence of age and education on neuropsychological performances of persons with mild head injuries. Appl Neuropsychol 1997;4:16-33.

[42] Dikmen S, Machamer J, Temkin N. Mild head injury: facts and artifacts. J Clin Exp Neuropsychol 2001;23:729-38.

[43] Taylor AE, Cox CA, Mailis A. Persistent neuropsychological deficits following whiplash: evidence for chronic mild traumatic brain injury? Arch Phys Med Rehabil 1996;77:529-35.

[44] Heitger MH, Anderson TJ, Jones RD. Saccade sequences as markers for cerebral dysfunction following mild closed head injury. Prog Brain Res 2002;140:433-48.

[45] Heitger MH, Jones RD, Dalrymple-Alford JC, Frampton CM, Ardagh MW, et al. Motor deficits and recovery during the first year following mild closed head injury. Brain Inj 2006;20:807-24.

[46] Heitger MH, Anderson TJ, Jones RD, Dalrymple-Alford JC, Frampton $\mathrm{CM}$, et al. Eye movement and visuomotor arm movement deficits following mild closed head injury. Brain 2004;127:575-90.

[47] Heitger MH, MacAskill MR, Jones RD, Anderson TJ. The impact of mild closed head injury on involuntary saccadic adaptation — evidence for the preservation of implicit motor learning. Brain Inj 2005;19:109-17.

[48] McAllister TW, Sparling MB, Flashman LA, Saykin AJ. Neuroimaging findings in mild traumatic brain injury. J Clin Exp Neuropsychol 2001;23:775-91.

[49] Ommaya AK. Head injury mechanisms and the concept of preventive management: a review and critical synthesis. J Neurotrauma 1995;12:527-46.

[50] Richardson JTE. Clinical and Neuropsychological Aspects of Closed Head Injury. Brain Damage, Behaviour and Cognition Series. Hove (UK): Psychology Press; 2000.

[51] Levin HS, Mattis S, Ruff RM, Eisenberg HM, Marshall LF, et al. Neurobehavioral outcome following minor head injury: a three-center study. J Neurosurg 1987;66:234-43.

[52] Hanlon RE, Demery JA, Martinovich Z, Kelly JP. Effects of acute injury characteristics on neurophysical status and vocational outcome following mild traumatic brain injury. Brain Inj 1999;13:873-87.

[53] King NS, Crawford S, Wenden FJ, Caldwell FE, Wade DT. Early prediction of persisting post-concussion symptoms following mild and moderate head injuries. Br J Clin Psychol 1999;38:15-25.

[54] Stambrook M, Moore AD, Peters LC, Deviaene C, Hawryluk GA. Effects of mild, moderate and severe closed head injury on long-term vocational status. Brain Inj 1990;4:183-90.

[55] Muir SR, MacAskill MR, Herron D, Goelz H, Jones RD, et al. EMMAan eye movement measurement and analysis system. Australas Phys Eng Sci Med 2003;26:18-24

[56] Reulen JPH, Marcus JT, Koops D, de Vries FR, Tiesinga G, et al. Precise recording of eye movement: the IRIS technique part 1 . Med Biol Eng Comput 1988;26:20-6.

[57] Jones RD. Measurement of sensory-motor control performance capacities: tracking tasks. In: Bronzino JD, editor. The Biomedical Engineering Handbook, 2nd Ed., vol. 149. Boca Raton (FL): CRC Press; 2000. p. 1-25.

[58] Gronwall DMA. Paced Auditory Serial Addition Test (PASAT). Victoria, Canada: Department of Psychology, University of Victoria; 1977.
[59] Delis DC, Kramer, JH, Kaplan, E, Ober, BA. California Verbal Learning Test (CVLT). San Antonio: The Psychological Corporation ${ }^{\circledR}$, Harcourt Brace and Company, 1987.

[60] Smith A. Symbol Digit Modalities Test. Los Angeles, California: Los Angeles, USA: Western Psychological Services; 1973.

[61] Spreen O, Strauss E. A Compendium of Neuropsychological Tests. New York: Oxford University Press; 1991.

[62] The Psychological Corporation. Wechsler Abbreviated Scale of Intelligence-Manual. San Antonio: The Psychological Corporation; 1999.

[63] Ware JE, Kosinski M, Dewey JE. How to Score Version Two of the SF36 Health Survey. Lincoln, RI: QualityMetric Incorporated; 2000.

[64] King NS, Crawford S, Wenden FJ, Moss NE, Wade DT. The Rivermead Post Concussion Symptoms Questionnaire: a measure of symptoms commonly experienced after head injury and its reliability. J Neurol 1995;242:587-92.

[65] Crawford S, Wenden FJ, Wade DT. The Rivermead head injury follow up questionnaire: a study of a new rating scale and other measures to evaluate outcome after head injury. J Neurol Neurosurg Psychiatry 1996;60:510-4.

[66] Bazarian J, Hartman M, Delahunta E. Minor head injury: predicting follow-up after discharge from the Emergency Department. Brain Inj 2000;14:285-94.

[67] Reitan RM, Wolfson D. The significance of sensory-motor functions as indicators of brain dysfunction in children. Arch Clin Neuropsychol 2003;18:11-8.

[68] Leigh RJ, Zee DS. The Neurology of Eye Movements-Third Ed. Contemp Neurol Ser. New York: Oxford University Press; 1999.

[69] Bittencourt PR, Wade P, Smith AT, Richens A. The relationship between peak velocity of saccadic eye movements and serum benzodiazepine concentration. Br J Clin Pharmacol 1981;12:523-33.

[70] Thier P, Dicke PW, Haas R, Thielert CD, Catz N. The role of the oculomotor vermis in the control of saccadic eye movements. Ann NY Acad Sci 2002;978:50-62.

[71] Enderle JD. Neural control of saccades. Prog Brain Res 2002;140: $21-49$.

[72] Ommaya AK, Gennarelli TA. Cerebral concussion and traumatic unconsciousness. Correlation of experimental and clinical observations of blunt head injuries. Brain 1974;97:633-54.

[73] Watson MR, Fenton GW, McClelland RJ, Lumsden J, Headley M, et al. The post-concussional state: neurophysiological aspects. Br J Psychiatry $1995 ; 167: 514-21$.

[74] Fenton GW. The postconcussional syndrome reappraised. Clin Electroencephalogr 1996;27:174-82.

[75] Levin HS, Williams D, Crofford MJ, High Jr WM, Eisenberg HM, et al. Relationship of depth of brain lesions to consciousness and outcome after closed head injury. J Neurosurg 1988;69:861-6.

[76] Pierrot-Deseilligny C, Muri RM, Ploner CJ, Gaymard B, RivaudPechoux S. Cortical control of ocular saccades in humans: a model for motricity. Prog Brain Res 2003;142:3-17. 